\title{
Oviposition Model for Timing Insecticide Sprays Against Plum Curculio (Coleoptera: Curculionidae) in New York State
}

\author{
W. H. REISSIG, J. P. NYROP, AND R. STRAUB \\ Department of Entomology, New York State Agricultural Experiment Station, Barton Laboratory, Cornell University, \\ Geneva, NY 14456
}

\begin{abstract}
Environ. Entomol. 27(5): 1053-1061 (1998)
ABSTRACT Plum curculio, Conotrachelus nenuphar (Herbst), feeding and oviposition on apples during spring was measured for $3 \mathrm{yr}$ in a heavily infested orchard in New York State. A logistic model was formulated to relate cumulative fruit injury to cumulative heat units (degree-days base $10^{\circ} \mathrm{C}$ $\left[D_{10}\right]$ ) following petal fall. Cumulative plum curculio injury was well described by the model in the trees from which data for the model were collected. However, injury progressed faster and ended earlier in smaller trees at the same site and at a different site, probably because of differences in tree architecture. Field trials showed that protection of the fruit via insecticide residue was no longer necessary after the model predicted that $40 \%$ of the cumulative plum curculio oviposition and feeding cycle had been completed ( $171 \mathrm{DD}_{10}$ after petal fall). Based on historical weather records, use of the model to schedule insecticide treatments would save 1 insecticide application nearly half the time compared with a standard of 3 insecticide applications. A delay between initial plum curculio feeding and oviposition, which coincides with the petal fall, phenophase, and steadily increasing damage, which is influenced by temperatures after petal fall was observed. The effectiveness of delaying insecticide treatments until the rate of plum curculio damage was rapidly increasing was compared with treatments applied at petal fall. Delaying the lst insecticide application resulted in higher levels of damage compared with making the lst treatment immediately after petal fall.
\end{abstract}

KEY WORDS Conotrachelus nenuphar, phenology model, decision guide

Plum CuHculio, Conotrachelus nenuphar (Herbst), is a native pest of apples and stone fruits in eastern North America (Chapman 1938). Damage to fruit occurs as a result of adult feeding and oviposition. Most apple orchards in the northeastern United States and Canada are treated every year with insecticides to control this pest (Hoyt et al. 1983, Reissig et al. 1984). Insecticides used to control plum curculio are usually applied on a schedule that coincides with tree phenology. Spring development of apple trees proceeds through a series of stages (phenophases) commonly refered to as silver tip, green tip, pink, flowering, and petal fall (Chapman and Catlin 1976). Insecticides are usually applied initially at either pink or petal fall and are designed to kill adults immigrating from sources outside the orchard (Chouinard et al. 1992). Usually at least 1 other nsecticide spray is applied 10-14 d after the petal fall spray, and a 3rd application may be applied near the end of the curculio's oviposition cycle (Chouinard et al. 1992, Racette et al. 1992).

Although emergence patterns of plum curculio adults from overwintering habitats are strongly influenced by spring weather conditions and are variable from year to year, the presence of adults in apple trees in commercial orchards is linked to apple phenology. A few beetles may be detected in apple trees as early as the green tip stage, and populations of adults gradually increase in commercial orchards during the pink and bloom stages. Adults continue to immigrate into apple trees after bloom and, depending upon the weather, the highest populations usually occur 10-15 d after petal fall (Whitcomb 1929, Chapman 1938, Lathrop 1949, Paradis 1956).

Even though relatively large populations of plum curculio adults may be present in commercial orchards during the pink and bloom phenophases, they generally do not begin to feed or oviposit within the fruit until after petal fall (Chapman 1938). The onset of oviposition is probably primarily influenced by the size of the developing fruit and by temperature and weather conditions although the physiological development of plum curculio adults also may be a factor (Lathrop 1949).

Most studies have shown that plum curculio activity and oviposition are strongly influenced by temperature. Activity decreases with temperatures between 29 and $133^{\circ} \mathrm{C}$, and very few eggs are laid when insects are held at $13^{\circ} \mathrm{C}$ (Whitcomb 1932). Early in the oviposition cycle, there is a relationship between temperature and the number of plum curculio present in apple trees (Lathrop 1949). This may occur because daily movement of curculios is greater with higher average spring temperatures (Racette et al. 1991). There is also a positive relationship between average 5-d temperature and oviposition (Lathrop 1949); however, rates of oviposition in the evening are not correlated with daily temperature (Owens 1982). 
Orchardists are aware that plum curculio activity and oviposition patterns are strongly influenced by spring weather and that more insecticide applications may be required to protect fruit during cool seasons. Various techniques have been used to monitor plum curculio adults or damage in apple orchards to determine if control is needed and to better synchronize insecticide applications with plum curculio immigration and fruit damage. Monitoring methods have included jarring limbs to dislodge adults; trapping adults moving into orchards; placing 'Granny Smith' apples in trees prior to fruit set to detect early oviposition; and periodically sampling fruit along orchard borders to monitor oviposition activity (Chapman 1938, LeRoux 1961, Prokopy et al. 1980, LeBlanc et al. 1984, Schmitt and Berkett 1995). All of these techniques require considerable time, labor, and expertise, and may not be sufficiently accurate or provide adequate time for growers to apply insecticide sprays to prevent fruit damage. Consequently, most insecticide sprays directed at plum curculio are applied on a protective schedule that is based on apple tree phenology and fruit development. Such fixed-schedule spraying can result in unessecary pesticide application, with attendant monetary loss and environmental risks. The objectives of this study were to develop a heat-based model to predict plum curculio fruit injury and to determine whether the model could be used to improve the timing of insecticide sprays used to control this pest.

\section{Materials and Methods}

Plum curculio damage in commercial apple orchards results from 2 processes: movement of adults into orchards and feeding and oviposition by adults on and in apples (fruit puncturing). Immigration and fruit puncturing occur sequentially; therefore, the former is completed before the latter. Insecticide residues need persist only until the completion of immigration. The rate of fruit puncturing is temperature dependent; we assume that immigration shows a similar relationship to temperature. If this assumption is correct, then accumulated fruit puncturing can be used as a proxy measure of immigration.

The time course of fruit puncturing is relatively easy to measure so we tested these ideas by doing the following. First, we measured plum curculio feeding and oviposition and used these measurements to formulate a model that described cumulative plum curculio injury to fruit based on heat units accumulated after petal fall. These measurements and model parameter estimates were made during each of $3 \mathrm{yr}$, beginning in 1991. Second, during the 1st yr of the study we applied insecticides so that residues would be present during varying lengths of the feeding and oviposition cycle. We used the results from this experiment with the observed pattern of cumulative fruit damage to formulate a guide as to when insecticide residues must be present to achieve effective control. Third, we tested the resulting decision guide during the 2nd and 3rd yr of the study.
Measuring Plum Curculio Oviposition. Plum curculio fruit puncturing was measured in 2 research orchards at the New York State Agricultural Experiment Station, Geneva, NY, and in an orchard at the Hudson Valley Horticultural Research Laboratory, Highland, NY. One orchard at Geneva was heavily infested with plum curculio. Data from this orchard were used to formulate the temperature-driven model for plum curculio damage to fruit. Trees used in this study were not sprayed with any insecticides but received a normal schedule of fungicides to protect them from apple scab and other diseases. In 1991, 1992, and 1993, plum curculio feeding and oviposition was measured in 6 'McIntosh' trees from this orchard that were about $25 \mathrm{yr}$ old and $4.6 \mathrm{~m}$ high.

In 1992 plum curculio feeding and oviposition was also measured in 6 'Delicious' apple trees (each $2.3 \mathrm{~m}$ tall) in an orchard adjacent to the one previously described. Finally, oviposition was measured during 1992 and 1993 in 6 'McIntosh' apple trees (each $2.3 \mathrm{~m}$ tall) from an orchard located at Highland.

The following technique was used to measure plum curculio feeding and oviposition. During bloom, 20 fruit clusters were selected from around the periphery of each tree and marked with a small linen tag attached to the bottom of the branch spur. At Geneva, on Monday, Wednesday, and Friday of each week during the test, the same marked clusters were examined and number of fruit, oviposition scars, and feeding punctures was counted and recorded. Observations began in each cultivar when $\approx 90 \%$ of the petals had fallen and continued until no additional feeding sites or fresh oviposition scars were observed. Observation dates were from 13 May-20 June in 1991, 22 May-13 July in 1992, and 19 May-2 July in 1993. Temperature during the monitoring period was recorded at a meteorological station maintained by the New York State Agricultural Experiment Station located $\approx 50 \mathrm{~m}$ from the research orchard.

At Highland, counts were made the same way except that observations were taken every 3 to $5 \mathrm{~d}$. Temperatures were recorded at a meteorological station maintained by the Hudson Valley Horticultural Research Laboratory. Observation dates were from 18 May-6 July in 1992 and 11 May-24 June in 1993.

Model for Temporal Pattern of Plum Curculio Camage to Fruit. We expressed plum curculio damage on a per fruit basis by dividing the number of feeding punctures and oviposition scars by the number of fruit examined from each tree and then by calculating an average for the set of trees $(n=6)$. Using average damage per fruit, we then calculated cumulative proportional damage by dividing each estimate by the maximum value observed.

Damage was expressed on a per fruit basis to reduce bias caused by fruit drop. During the period when plum curculio injure fruit, fruit naturally abscise. Some fallen fruit contain feeding punctures or oviposition scars or both, and as a result, estimates of total wounds increased to a maximum and then declined (because of fruit drop) even while new egg-laying scars were appearing. Expressing damage on a per fruit 
basis eliminated this aberrant pattern. Ideally, recording damage on a per fruit basis requires that the abscision rate of damaged and undamaged fruit be the same within a growing season, among growing seasons, and among orchards for there not to be bias in this estimator. This condition is probably not met as Levine and Hall (1977) showed that the presence of plum curculio larvae caused increased fruit drop, although plum curculio feeding and egg-cavity preparation alone did not cause fruit abscission. Although our estimator of damage per fruit likely has some bias, there are no other workable alternatives.

We fit the estimates of cumulative proportion damage (cpd) obtained in 1991 to a 3 parameter logistic function with degree-days (base $10^{\circ} \mathrm{C}$ ) after petal fall $\left(\mathrm{DD}_{10}\right)$ as the independent variable:

$$
\operatorname{cpd}=\frac{b_{1}}{\left[1+\mathrm{e}^{\left(-b_{2} *\left[D D_{10}-b_{1}\right]\right)}\right]}
$$

Parameter estimates (of $b_{1}, b_{2}$, and $b_{3}$ ) were obtained using nonlinear least squares (StataCorp 1997).

We followed a similar procedure in 1992 and 1993 and studied parameter estimates among years by comparing their confidence intervals. We also estimated model parameters when equation [1] was fit to the combined data from 1991 and 1992 and from 19911993. We compared predictions from the model parameterized from 1991 data to 1992 data, and from a model parameterized from 1991 and 1992 data to 1993 data. We also compared predictions from a model estimated from the 1991-1993 data to estimates from Delicious trees at Geneva and McIntosh trees at Highland. These comparisons were all made using the Kolmogorov-Smirnov test (StataCorp 1997).

Timing Plum Curculio Sprays Based on Model Predictions. In 1991 we conducted an experiment whose purpose was to synchronize duration of insecticide residue with plum curculio fruit puncturing to maximize control effectiveness. We tested our hypothesis that insecticide need not be present for the entire oviposition period by providing 4 intervals of insecticide residue and measuring subsequent plum curculio damage. This experiment was conducted in the same orchard in which feeding and oviposition damage was measured to parameterize the model, thereby allowing comparison of the results from the 2 experiments.

Treatments consisted of 4 intervals of insecticide residue and a control (Table 1): (1) a complete protective residue that started at the pink bud phenophase and was assumed to expire 19 June (14 d after the last treatment); (2) a standard residue that started at petal fall and was assumed to expire 19 June; (3) a reduced residue that started at petal fall and was assumed to expire 8 June and (4) a minimal residue that started at petal fall and was assumed to expire 28 May. Treatments were arranged in a randomized complete block design and replicated 3 times. Replicates consisted of single trees separated from other trees on all sides by single, unsprayed trees. Insecticide sprays were applied with a truck-mounted high-pressure
Table 1. Insecticide applications made to vary duration of insecticide residues for control of plum curculio in 1991

\begin{tabular}{ccccc}
\hline & \multicolumn{4}{c}{ Insecticide applications } \\
\cline { 2 - 5 } Treatment $\begin{array}{c}\text { 1 May } \\
\text { (pink bud stage) }\end{array}$ & $\begin{array}{c}\text { 14 May } \\
\text { (petal fall) }\end{array}$ & $\begin{array}{c}24 \text { May } \\
\text { (1st cover) }\end{array}$ & $\begin{array}{c}5 \text { June } \\
\text { (2nd cover) }\end{array}$ \\
\hline $\begin{array}{c}\text { Protective } \\
\text { residue }\end{array}$ & $\mathrm{E}^{a}$ & $\mathrm{~A}^{L}$ & $\mathrm{~A}$ & $\mathrm{~A}$ \\
$\begin{array}{c}\text { Standard } \\
\text { residue } \\
\begin{array}{c}\text { Reduced } \\
\text { residue }\end{array}\end{array}$ & $\mathrm{A}$ & $\mathrm{A}$ & $\mathrm{A}$ \\
$\begin{array}{c}\text { Minimal } \\
\text { residue }\end{array}$ & $\mathrm{A}$ & $\mathrm{A}$ & \\
\hline
\end{tabular}

"Esfenfalerate, $8.2 \%$ emulsifiable concentrate, $0.04 \mathrm{~g}$ (AI)/liter.

${ }^{b}$ Azinphosmethyl, $35 \%$ wettable powder, $0.3 \mathrm{~g}$ (AI) /liter.

handgun until the foliage was saturated. Fruit damage was evaluated by examining 50 dropped and 100 picked apples from each tree on 14 August and recording each fruit as damaged or undamaged. To reduce selection bias, 25 consecutive fruit were picked from a point randomly located in each quadrat of each tree. For dropped apples, 25 consecutive apples were examined from each of 2 randomly located points beneath each tree. Data were transformed as arcsine $(\sqrt{\mathrm{x}})$ prior to analysis to reduce heteroscedastisity. Means were separated using Fisher's protected least significant difference (LSD) test $(P<0.05)$ (Statistical Sciences 1995).

Based on the results from the aforementioned experiment, we formulated guidelines as to when insecticide residues are needed to control plum curculio damage to fruit. These guidelines consisted of maintaining an insecticide residue until 40 or $60 \%$ of fruit puncturing was complete and delaying the 1st insecticide spray until $\approx 80 \mathrm{DD}_{10}$ had accumulated after petal fall.

In 1992 we tested these guidelines by conducting an experiment in which these tactics were compared to 3 other levels of insecticide residue and a control (Table 2). Treatments consisted of the the following: (1) a protective residue that started at the pink phenophase was assumed to expire 27 June ( $14 \mathrm{~d}$ after the last treatment); (2) a standard residue that started at petal fall and was assumed to expire 27 June; (3) a residue that originated at petal fall and provided residue until the model predicted that $40 \%$ of fruit puncturing had occured $\left(190 \mathrm{DD}_{10}\right)$; (4) a more conservative model predicted residue duration that originated at petal fall and provided residue until $60 \%$ of total feeding and oviposition was predicted (230 $\mathrm{DD}_{10}$ after petal fall); and 5) a delayed model-predicted residue duration that originated $80 \mathrm{DD}_{10}$ after petal fall and provided residue until $40 \%$ of total fruit puncturing was predicted. Treatment dates, insecticides used, and application rates are given in Table 2. Treatments were applied to individual trees as described in the previous experiment, with 6 replicates and arranged in a randomized block design. Fruit damage was estimated twice; once on 6 July and again on 28 August. On 6 July 100 fruit on each tree were 
Table 2. Insecticide applications made to test decision guides hased on a phenology model for plun curculio feeding and oviposition

\begin{tabular}{|c|c|c|c|c|c|c|}
\hline \multirow{3}{*}{$\begin{array}{l}1992 \text { treatments } \\
1993 \text { treatments }\end{array}$} & \multicolumn{6}{|c|}{ Insecticide applications } \\
\hline & 13 May $^{a}$ & $22 \mathrm{May}^{b}$ & 4 June ${ }^{c}$ & 5 June & 13 June & \\
\hline & 8 May & $18 \mathrm{May}$ & $28 \mathrm{May}^{d}$ & 4 June & 15 June & 28 June \\
\hline Protective & $\mathrm{E}^{f} f$ & $A^{g}$ & & $A$ & A & \\
\hline Residue & $\mathrm{E}$ & $A$ & & A & $\mathbf{A}$ & A \\
\hline \multirow[t]{2}{*}{ Standard residue } & & A & & $\mathbf{A}$ & $A$ & \\
\hline & & $A$ & & $\mathbf{A}$ & $\mathbf{A}$ & \\
\hline \multirow[t]{2}{*}{ 40th percentile model } & & $\mathbf{A}$ & & A & & \\
\hline & & $A$ & & A & $\mathbf{A}$ & \\
\hline \multirow[t]{2}{*}{60 th percentile model } & & $A$ & & $\mathbf{A}$ & $\mathbf{A}$ & \\
\hline & & A & & $\mathbf{A}$ & $\mathbf{A}$ & A \\
\hline Delayed 40th & & & A & & & \\
\hline Percentile model & & & $A$ & & $A$ & \\
\hline
\end{tabular}

a Pink bud stage of tree development.

'Petal fall stage of tree development.

c $83 \mathrm{DD}_{10}$ after petal fall

' $40 \mathrm{nDD}_{10}$ after petal fall

c The 1st letter in each cell refers to 1992 application, 2nd letter to 1993 application. If a letter is missing, no application was made that year.

$f$ Esfenfalerate, $8.2 \%$ emulsifiable concentrate, $0.04 \mathrm{~g}$ (AI) $/$ liter.

g Azinphosmethyl, $35 \%$ wettable powder, $0.3 \mathrm{~g}$ (AI)/liter.

examined for plum curculio feeding wounds or oviposition punctures. Observer bias was reduced by choosing a starting point in each of the 4 quadrants of the tree and examing 25 consecutive fruit from each of these starting points. Each fruit was scored as either damaged or clean. On the 2 nd sample date 50 fruit that had fallen to the ground and 100 fruit on the tree were examined for feeding wounds or oviposition punctures. Observer bias for fruit on the trees was reduced as previously described. For fruit on the ground, 2 starting points on the ground beneath each tree were selected and 25 consecutive fruit from each of these points were examined. Each fruit was again scored as either damaged or clean. Data were transformed before analysis $[\operatorname{arcsine}(\sqrt{\mathrm{x}})]$ and subjected to multivariate repeated measures analysis of variance (ANOVA) (Statistical Sciences 1995). Even though the sample size used to estimate the proportion of damaged fruit on the two sample dates was different, data were weighted the same in the ANOVA. Treatment means were separated using Fisher protected LSD test $(P<0.05)$.

The experiment conducted in 1992 was repeated in 1993. Dates of insecticide applications are listed in Table 2 . The delayed model-predicted residue schedule was modified so that the lst insecticide application was made $40 \mathrm{DD}_{10}$ after petal fall (28 May). This shorter delay period was selected because results obtained in 1992 showed that delaying the petal fall spray by $80 \mathrm{DD}_{10}$ allowed too much damage to occur before the 1st spray was applied. A 3rd insecticide application after petal fall was required to provide insecticide residue until $60 \%$ cumulative plum curculio damage was predicted to have occurred. As a result, a 3rd application also was made in the protective residue treatment. Fruit damage was estimated twice; once on 20 July and again on 13 September. Estimates on each date were obtained using the same procedure as in 1992. Data were transformed before analysis / arcsine $(\sqrt{x})]$ and subjected to multivariate repeated mea- sures ANOVA (Statistical Sciences 1995). Treatment means were separated using Fisher protected LSD test $(P<0.05)$.

\section{Results}

Model for Temporal Pattern of Plum Curculio Damage to Fruit. Between 70 and $80 \%$ of all injuries recorded on McIntosh fruit at Geneva resulted from oviposition. Calendar dates for the temporal pattern of plum curculio damage to this fruit varied from year to year (Fig. 1A). In 1991, the 1st damage was observed on $15 \mathrm{May}$, only $\approx 1 \mathrm{~d}$ after petal fall, median damage occurred $\approx 3$ June, and damage was nearly complete by 28 June. In 1992, damage was 1st observed on 22 May, median damage on 15 June, and damage was nearly complete by 13 July. In 1993, damage was 1st recorded on 31 May, median damage occurred around 19 June, and damage was completed by 30 June.

Each year the data recorded from the McIntosh fruit in Geneva were well described by equation $1\left(r^{2}\right.$ $>0.99$ ). Model fits to each year's data are shown in Fig. $1 \mathrm{~A}$ and parameter estimates are given in Table 3. Of the models fit to these data, those for years 1991 and 1993 had parameters whose confidence intervals overlapped, whereas parameters estimated from the 1992 data were significantly different from the other 2 sets. Following collection of the 1992 data, equation 1 was fit to the combined 1991 and 1992 data, and in 1993 equation 1 was fit to the data from all $3 \mathrm{yr}$. Parameter estimates for these models also are shown in Table 3. When predictions from the model fit to the 1991 data were compared with the 1992 field estimates, predicted phenology was significantly later than observed (maximum difference between observed and predicted $=0.26, P<0.01$ ). When predictions from the model fit to the 1991 and 1992 data were compared with the 1993 field estimates, there was no significant difference between the two distributions. A single model fit to all $3 \mathrm{yr}$ of data explained approximately 
Plum curculio damage at Geneva 1991-1993

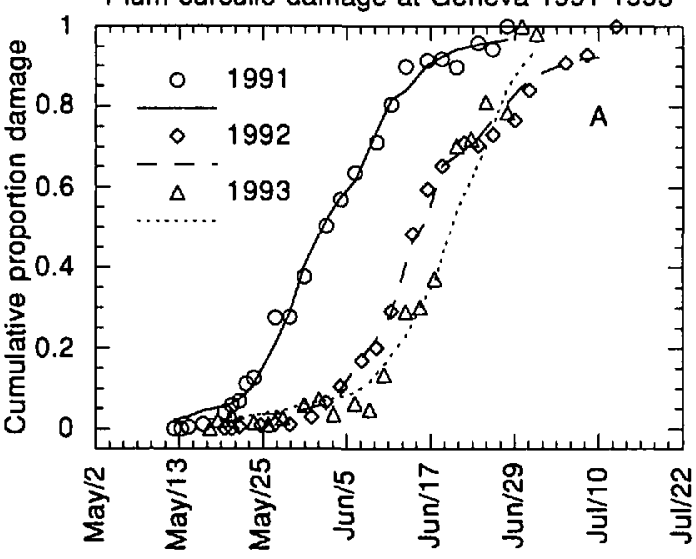

Plum curculio damage at Geneva 1991-1993

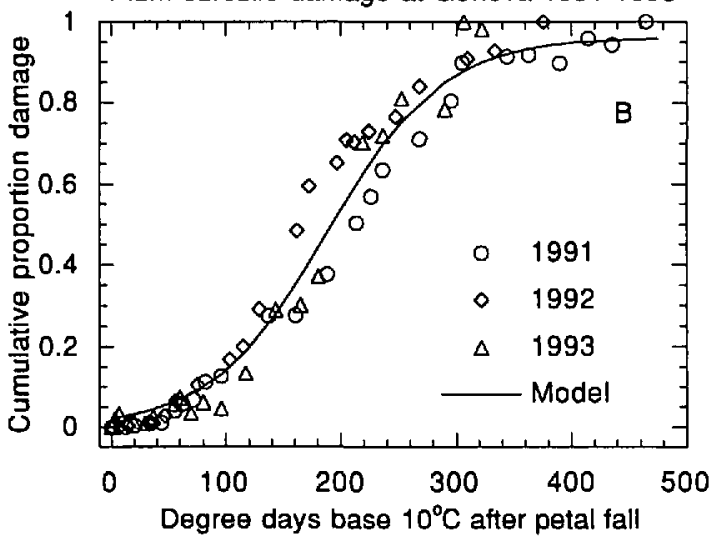

Fig. 1. Cumulative plum curculio damage in McIntosh trees at Geneva, NY, during 1991-1993 as a proportion of maximum observed damage. (A) Data shown in relation to calender date; lines are models fit to each year's data. (B) Data shown in relation to $\mathrm{DD}_{10}$ after petal fall; line is from a single model fit to all 3 yr of data.

$98 \%$ of the variation in cumulative proportion damage (Fig. 1B; Table 3).

When predicted values from models parameterized using data collected from the McIntosh trees at Geneva were compared with either damage in Delicious
Predicted and observed Plum curculio damage in Red Delicious trees at Geneva 1992

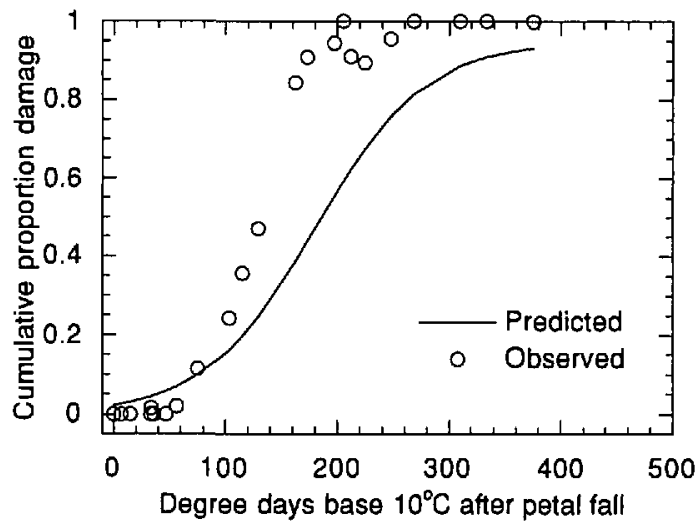

Predicted and observed Plum curculio damage in Mclntosh trees at Highland 1992 \& 1993

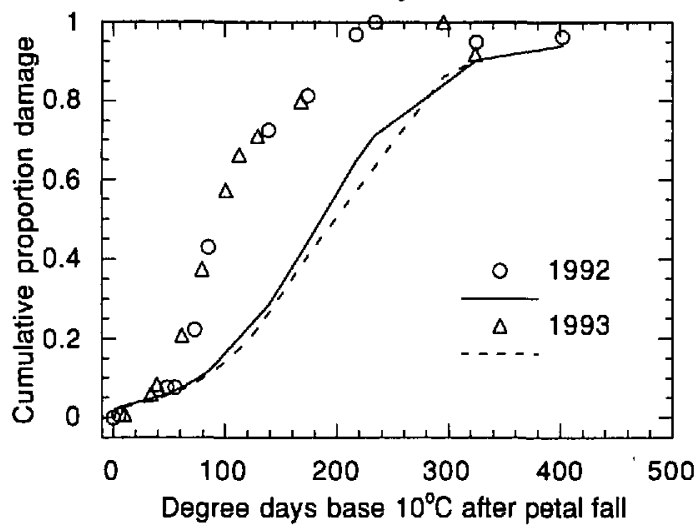

Fig. 2. Predicted and observed plum curculio damage in Red Delicous trees at Geneva, NY, and McIntosh trees at Highland, NY. Predicted values are from models fit to data collected from 'McIntosh' trees at Geneva, NY; 1992 predictions from a model fit to data from 1991 and 1992 and 1993 predictions from a model fit to data from 1991-1993.

trees at Geneva, or McIntosh trees at Highland, model predictions were always significantly $(P<0.01)$ later than observed values (Fig. 2). Although the model predictions were not in close agreement to the observed pattern of damage to fruit at Highland, the data

Table 3. Coefficients for a hent driven model of cumulative proportion plum curculio danage

\begin{tabular}{|c|c|c|c|c|c|c|}
\hline \multirow{2}{*}{ Year } & \multicolumn{2}{|c|}{$b_{1}$} & \multicolumn{2}{|c|}{$b_{2}$} & \multicolumn{2}{|c|}{$b_{3}$} \\
\hline & Coefficient & SE & Coefficient & SE & Coefficient & $\mathrm{SE}$ \\
\hline 1991 & 0.9746 & 0.0155 & 0.0103 & 0.0005 & 372.95 & 6.347 \\
\hline 1992 & 0.9315 & 0.0198 & 0.0138 & 0.0008 & 291.98 & 6.018 \\
\hline 1993 & 1.1172 & 0.0911 & 0.0095 & 0.0009 & 402.04 & 23.112 \\
\hline 1991,1992 & 0.9487 & 0.0241 & 0.0114 & 0.0009 & 324.93 & 8.934 \\
\hline $1991-1993$ & 0.9615 & 0.0237 & 0.0111 & 0.0008 & 338.81 & 8.209 \\
\hline
\end{tabular}

Year indicates the data to which the model was fit. The $r^{2}$ values are $>0.98$ for all models and probabilities of larger $F$ statistics are approximately zero. 
Table 4. Proportion of fruit with plum curculio damage in 4 insecticide residue schedules at Geneva, NY, during 1991

\begin{tabular}{llc}
\hline \multirow{2}{*}{ Treatment } & \multicolumn{2}{c}{ Damage } \\
\cline { 2 - 3 } & Mean & SD \\
\hline Protective residue & $0.035 \mathrm{a}$ & 0.019 \\
Standard residue & $0.099 \mathrm{a}$ & 0.112 \\
Reduced residue & $0.079 \mathrm{a}$ & 0.027 \\
Minimal residue & $0.273 \mathrm{~b}$ & 0.127 \\
Control & $0.413 \mathrm{~b}$ & 0.119 \\
\hline
\end{tabular}

Means within a column followed by the same letter are not significantly different $(P<0.05$; Fisher protected LSD)

from the 2 yr at Highland were nearly identical. Furthermore, the pattern of damage observed in Delicious trees at Geneva was not significantly different from the pattern observed in McIntosh trees at Highland.

Although plum curculio damage was lst observed shortly after petal fall in all $3 \mathrm{yr}$, damage usually remained low in the monitored fruit for days after petal fall, and then began to steadily increase. For example, in 1991, the 1st damage on McIntosh apples was observed on 15 May, but the average number of punctures per fruit was $<0.02$ until 20 May. A similar delay in the increase in damage in McIntosh fruit from petal fall (25 May) until 3 June was observed in 1992, and also in 1993, when damage remained low from the initial observation on 31 May until 9 June. A similar delay between the onset of fruit puncturing and steadily increasing damage after petal fall also was observed in Delicious apples at Geneva, but it was not as apparent in McIntosh apples at Highland (Fig. 2).

Timing Plum Curculio Sprays Based on Model Predictions. Our estimates of plum curculio feeding and oviposition showed that damage continued to accrue to fruit through late June or early July. However, New York orchardists usually do not apply insecticides to control plum curculio during the end of the egg-laying period. The studies conducted in 1991 to compare the effectiveness of different durations of insecticide residue to control plum curculio damage supported these pest control practices. Overall, the ANOVA showed there were significant differences in plum-curculiodamaged fruit among the 5 treatments $(F=8.857$; $\mathrm{df}=$ $4,10 ; P<0.05)$. A single insecticide application at petal fall did not provide sufficient insecticide residue to adequately control plum curculio damage because percentage of damaged fruit in this treatment was not significantly different from that in the unsprayed check (Table 4). However, neither the protective residue program (4 insecticide applications) or the standard residue program (3 insecticide applications), which both would have protected fruit until oviposition was nearly complete in late June, were more effective in preventing damage than the reduced residue program (2 insecticide applications). Assuming that the residue from the last treatment in the reduced residue program, which was applied on 24 May, would have protected fruit for $\approx 14 \mathrm{~d}$ after treatment, the reduced residue program would have provided protection until $\approx 7$ June. This corresponded to $\approx 60 \%$ of
Table 5. Proportion of fruit with plum curculio damage in 6 insecticide residue schedules at Geneva, NY, during 1992 and 1993

\begin{tabular}{|c|c|c|c|c|}
\hline \multirow{3}{*}{ Treatment } & \multicolumn{4}{|c|}{ Damage } \\
\hline & \multicolumn{2}{|c|}{1992} & \multicolumn{2}{|c|}{1993} \\
\hline & Mean & $\mathrm{SD}$ & Mean & SD \\
\hline Protective residue & $0.031 \mathrm{a}$ & 0.022 & $0.007 \mathrm{a}$ & 0.012 \\
\hline Standard residue & $0.035 \mathrm{a}$ & 0.037 & $0.002 \mathrm{a}$ & 0.006 \\
\hline $\begin{array}{l}\text { 60th Percentile } \\
\text { model residue }\end{array}$ & $0.038 \mathrm{a}$ & 0.019 & $0.006 a$ & 0.009 \\
\hline $\begin{array}{l}\text { 40th Percentile } \\
\text { model residue }\end{array}$ & $0.033 a$ & 0.026 & $0.005 \mathrm{a}$ & 0.01 \\
\hline $\begin{array}{l}\text { Delayed } 40 \text { th percentile } \\
\text { model residue }\end{array}$ & $0.145 b$ & 0.053 & $0.027 \mathrm{~b}$ & 0.03 \\
\hline Control & $0.311 \mathrm{c}$ & 0.086 & $0.079 c$ & 0.077 \\
\hline
\end{tabular}

Values are least squares estimates for 2 sample dates each year. Means within a column followed by the same letter are not significantly different $(P<0.05$; Fisher protected ISD).

cumulative plum curculio injury to the McIntosh fruit during that year. Forty percent cumulative injury occurred $\approx 1$ wk earlier on 1 June. Based on these results, we tested 2 insecticide application schedules in 1992 and 1993. The first of these schedules was designed to maintain insecticide residue until the oviposition model had predicted that $40 \%$ of fruit puncturing had occurred, and the 2nd schedule was more conservative and designed to maintain insecticide residue until $60 \%$ of fruit puncturing had occurred. In both cases we assumed that the last insecticide application would protect fruit from plum curculio damage for $\approx 14 \mathrm{~d}$. We also tested an application schedule in which the 1st insecticide application was witheld until $80 \mathrm{DD}_{10}$ accumulated after petal fall and insecticide residues were maintained until $40 \%$ cumulative damage was estimated to have occurred. This strategy was based on the observed delay between petal fall and steadily increasing damage to fruit.

1992 Tests. McIntosh apples reached the petal fall stage on $22 \mathrm{May}$, and the model predicted that 40 and $60 \%$ of plum curculio feeding and oviposition should have occurred on 19 June (185 $\mathrm{DD}_{10}$ ) and 29 June $\left(230 \mathrm{DD}_{10}\right)$, respectively. Repeated measures ANOVA showed significant differences in fruit damage among the insecticide residue schedules $(F=54.8$; $\mathrm{df}=5,30 ; P<0.01)$; however, there was no difference between the 2 sample dates nor was there a date by treatment interaction. There were no differences in proportion of plum-curculio-damaged fruit among the protective, standard, 40th percentile model, or 60th percentile model residue schedules (Table 5). Where treatment was delayed until $80 \mathrm{DD}_{10}$ after petal fall, damage occurred to $\approx 5$ times as many fruit as in the aforementioned treatments, and the control trees suffered approximately $\approx 2$ times this amount of damage (Table 5). The residue from the delayed petal fall spray, which was applied on 4 June after $83 \mathrm{DD}_{10}$ had accumulated, should have lasted long enough to protect fruit until $40 \%$ of the oviposition cycle had been completed on 18 June. The lack of effectiveness of this treatment must therefore be attributed to plum curculio injury incurred before the insecticide treatment 
because the treatment on 4 June and the 2 nd insecticide application made for the 40 th percentile model scheduled residue were only $1 \mathrm{~d}$ apart. The modelbased residue schedule that was designed to protect fruit until $40 \%$ of feeding and oviposition was complete was just as effective as both the treatment designed to protect fruit until $60 \%$ of feeding and oviposition was complete and the standard residue schedule, and required 1 less insecticide than the other 2 schedules (Table 2). The protective residue, which began with an application of an insecticide at pink, was not more effective in preventing plum curculio damage than any of the other programs.

1993 Tests. McIntosh trees reached the petal fall stage on 18 May and model predicted dates of 40 and $60 \%$ cumulative plum curculio feeding and oviposition were 17 and 22 June. Because of the cooler weather following petal fall, 2 insecticide applications were required after petal fall in the 40th percentile model residue schedule and 3 insecticide applications were required after petal fall in the 60 th percentile model residue schedule. Because 3 insecticide applications were made in the 60th percentile model residue schedule, 3 applications also were made after petal fall in the protective residue schedule. The 1st insecticide application under the delayed model-predicted residue schedule was applied on 28 May; 1 additional insecticide application was required in this program to provide residue through the predicted $40 \%$ cumulative feeding and oviposition.

Plum curculio damage was much lower in all treatments in 1993 than in 1992, but the patterns of damage among treatments were similar in both years. Repeated measures ANOVA showed significant differences among treatment means $(F=8.5 ; \mathrm{df}=5,30 ; P<$ 0.01 ); however, there was no difference between the 2 sample dates nor was there a date $x$ treatment interaction. There were no differences among the 4 treatments that included an insecticide application at petal fall (protective residue, standard residue and 40th and 60th percentile model) (Table 5). Damage in the treatment where the 1st insecticide application was delayed until $40 \mathrm{DD}_{10}$ after petal fall was $\approx 5$ times greater than in the previously described 4 treatments and damage in the control was $\approx 2$ times higher than this (Table 5). Although more insecticide applications were made in 1993 than in 1992, the 40th percentile model schedule limited plum curculio damage as well as any other treatment but with 1 less insecticide application. As in 1992, initiating plum curculio control at the pink bud stage did not reduce damage. Delaying the 1st insecticide treatment until $40 \mathrm{DD}_{10}$ after petal fall allowed higher levels of damage compared with initiating control at petal fall.

\section{Discussion}

We have shown that in an orchard heavily infested with plum curculio, it was not necessary to maintain insecticide residues on fruit and foliage for the duration of the oviposition cycle to effectively limit dam- age to fruit by this pest. The pattern of control provided by the different residue schedules was nearly the same in both years in which the experiment was conducted. There were no differences in damage among the treatments that included an insecticide application at petal fall. Of these treatments, maintaining insecticide residues until the model predicted 40th percentile for cumulative damage was reached required the fewest insecticide applications. This schedule required one less insecticide than the other 3 schedules in 1992, but required an equal number of insecticide applications as the standard schedule in 1993.

To estimate expected savings in pesticide applications from using the 40th percentile model predicted schedule compared with the standard 3-spray program, we calculated from records at Geneva the number of days from petal fall until $171 \mathrm{DD}_{10}$ had accumulated (40th percentile for cumulative damage) for the years 1986-1988 and 1990-1993. Assuming each application of insecticide provides $14 \mathrm{~d}$ of residual coverage, we also calculated the number of insecticide sprays that would be required using this schedule. There were $4 \mathrm{yr}$ in which 2 insecticide applications would have been needed and $3 \mathrm{yr}$ in which 3 applications were needed. For those years in which 3 insecticide applications would have been called for, the number of days from petal fall to 171 $\mathrm{DD}_{10}$ were 31,29 , and 30 , which are all just slightly greater than the 28 -d residual interval that would be provided by 2 insecticide applications. On average, use of the model to schedule insecticide treatments would save 1 insecticide application nearly half of the time.

The effectiveness of the 40th percentile model scheduled residue program is probably due to the behavior and activity patterns of the plum curculio. Various studies have shown that plum curculio adults become less active in trees after bloom and fruit set, that oviposition needs decline, and that movement of adults between trees declines (Racette et al. 1991, Chouinard et al. 1993). The 40th percentile for cumulative oviposition and feeding probably coincides with the cumulative heat units at which plum curculio activity wanes. Provided adults that are in trees at this point are killed, it is unlikely that trees will be reinfested by large numbers of beetles.

The phenological pattern of cumulative plum curculio damage suggested that the lst insecticide application could be delayed for some time after petal fall because there was a delay between the onset of plum curculio fruit puncturing and steadily increasing damage. This control strategy has been suggested before. In 1932, the following recommendations for controlling plum curculio adults were suggested to orchardists: "Wait five days after 'Petal Fall Stage' and then apply (the spray) as soon as the maximum temperature reaches $24^{\circ} \mathrm{C}$ or higher and promises to reach that temperature on 2 successive days" (Whitcomb 1932). However, our experiments indicate that this strategy is not as effective as applying an insecticide immediately after petal fall. This strategy could possibly be 
used in areas where plum curculio numbers are relatively low, and thereby eliminate one further insecticide application in about half the years. But, if large acreages are involved where several days are required to apply insecticides, this may be a risky strategy as plum curculio may begin to oviposit before some trees can be treated.

Applying insecticides before petal fall (at pink bud stage) to control plum curculio provided no additional reduction in the proportion of damaged fruit. Cumulative plum curculio feeding and oviposition in the McIntosh trees at Geneva was well described by the model driven by heat units after petal fall. However, the same process measured in the Delicious trees at Geneva and the McIntosh trees at Highland progressed at a faster rate and ended earlier than in the McIntosh trees at Geneva. This raises 2 questions; first, why did this difference occur and second, what are the implications of this difference for the broad use of the model to schedule insecticide applications?

We cannot provide a definitive reason for the differences observed in the feeding and oviposition processes among the sites. What we can do is tender a reasonable hypothesis as to why this happened. The McIntosh trees at Geneva in which data were collected for parameterizing the models were large, modestly pruned trees. In contrast, the Delicious trees at Geneva and the McIntosh trees at Highland were smaller trees $(<2.5 \mathrm{~m})$ that were well pruned. Fruit in well-pruned trees may be as much as $8^{\circ} \mathrm{C}$ warmer than fruit in poorly pruned trees due to more exposure to solar radiation (A. Lakso, personal communication). The difference in tree architecture among the sites in which we measured plum curculio feeding and oviposition probably allowed for different temperatures of fruit clusters, developing fruit, and twigs, which are sites where adult plum curculio rest during the daytime (Owens et al. 1982, Chouinard et al. 1992). As a result, plum curculio in the smaller, well-pruned trees may have experienced higher temperatures and hence accelerated physiological development. This would explain the faster pace of oviposition as well as the earlier termination of this process in the smaller trees.

The differences in phenological patterns observed among the sites suggests that the model for cumulative plum curculio is conservative, meaning that in smaller trees, it may not be necessary to maintain insecticide residues until the predicted 40 th percentile. This should be experimentally evaluated.

In summary, the model for cumulative feeding and oviposition developed in this study is effective for determining how long insecticide residues are needed to prevent damage after petal fall, and this information will be very helpful to apple growers planning postpetal fall insecticide programs. However, if an insecticide is applied promptly at petal fall and weather becomes cool, as it did during 1993, using the model will not reduce the number of insecticides applied for plum curculio control.

\section{Acknowledgment}

We thank Cindy Smith for overseeing collection and summary of data and a reviewer for helpful comments.

\section{References Cited}

Chapman, P. 1938. The plum curculio as an apple pest. N.Y. State Agric. Exp. Stn, Bull. 684.

Chapman, P. J., and G. A. Catlin. 1976. Growth stages in fruit trees-from dormant to fruit set. N.Y. Food and Life Sci. Bull. 58, Geneva, NY.

Chouinard, G., S. B. Hill, C. Vincent, and N. N. Barthakur. 1992. Border-row sprays for control of the plum curculio in apple orchards: behavoral study. J. Econ. Entomol. 85: $1307-1317$.

Chouinard, G., S. B. Hill, and C. Vincent. 1993. Spring behavior of the plum curculio (Coleoptera: Curculionidae) within caged dwarf apple trees. Ann. Entomol. Soc. Am. 86: $333-340$

Hoyt, S. C., J. R. Leeper, G. C. Brown, and B. A. Croft. 1983. Basic biology and management components for insect IPM, pp. 93-151. $h$ B. A. Croft and S. C. Hoyt [eds.], Integrated mnagement of insect pests of pome and stone fruits. Wiley, New York.

Lathrop. F. H. 1949. Biology of the plum curculio in Maine. J. Econ. Entomol. 42: 12-18.

LeBlanc, J.-P.R., S. B. Hill, and R. O. Paradis. 1984. Oviposition in scout green apples by plum curculio, Conotrachelus nenuphar (Herbst) (Coleoptera: Curculionidae) and its relationship to subsequent damage. Environ. Entomol. 13: 286-291.

Levine, E., and F. R. Hall. 1977. Effect of feeding and oviposition by the plum curculio on apple and plum abscission. J. Econ. Entomol. 70: 603-607.

LeRoux, E. J. 1961. Variation between samples of fruit, and of fruit damages mainly from insect pests, on apple in Quebec. Can. Entomol. 93: 680-694.

Owens, E. D., K. I. Hauschild, G. L. Hubbel, and R. J. Prokopy. 1982. Diurnal behavior of plum curculio (Coleoptera: Curculionidae) adults within host trees in nauture. Ann. Entomol. Soc. Am. 75: 357-362.

Paradis, R. O. 1956. Observations sur le cycle evolutif du charancon de la prune, Conotrachelus nenuphar ( $\mathrm{Hbst}$ ), sur la pomme dans le Quebec. Ann. Soc. Entomol. Que. 2: $60-70$.

Prokopy, R. J., W. M. Coli, R. G. Hislop, and K. I. Hauschild. 1980. Integrated management of insect and mite pests in commercial apple orchards in Massachusetts. J. Econ. Entomol. 73: 529-535.

Racette, G., G. Chouinard, S. B. Hill, and C. Vincent. 1991. Activity of adult plum curculio (Coleoptera: Curculionidae) on apple trees in spring. J. Econ. Entomol. 84: 1827-1832.

Racette, G., G. Chouinard, C. Vincent, and S. B. Hill. 1992. Ecology and management of the plum curculio, Conotrachelus neneuphar (Coleoptera: Curculionidae), in apple orchards. Phytoprotection 73: 85-100.

Reissig, W. H., R. W. Weires, C. G. Forshey, W. L. Roelofs, R. C. Lamb, and H. S. Aldwinckle. 1984. Insect management in disease-resistant dwarf and semi-dwarf apple trees. Environ. Entomol, 13: 1201-1207.

Schmitt, D., and L. P. Berkett. 1995. Evaluation of a new trap for monitoring plum curculio [Conotrachelus nenuphar (Herbst)] in New England apple orchards, pp. 109-113. In New England Fruit Meetings 1995. Massachusetts Fruit Growers Association, North Amherst, MA. 
Statistical Sciences. 1995. S-Plus user's manual, version 3.3 for Windows, Statistical Sciences, Seattle, WA.

Stata. 1997. Stata statistical software, release 5.0. Stata, College Station, TX

Whitcomb, W. D. 1929. The plum curculio in apples in Massachusetts. Mass. Agric. Exp. Stn. Bull. 249.
1932. The relation of temperature to the activity and control of the plum curculio in apples. Mass. Agric. Exp. Stn. Bull. 285: 1-16.

Received for publication 19 February 1997; accepted 1 April 1998. 